\title{
PENGARUH KUALITAS JASA TERHADAP KEPUASAN PENGUNJUNG OBYEK WISATA GUA PINDUL
}

\author{
Maricha Permata Putri \\ P.marichaputri@gmail.com
}

\begin{abstract}
Tourism is a product of the services offered by a service company in the hope that visitors come to visit and enjoy the attractions offered. In order to attract visitors, managers should be able to provide the best quality service to create a satisfaction to visitors. Quality of service has five dimensions include direct evidence (tangibles), reliability (reliability), responsiveness (reponsiveness), assurance (assurance) and empathy (empathy), the fifth dimension is referred to and used as a variable in this study in order to influence the quality of services to the satisfaction of visitor attractions Pindul. In this study is a qualitative approach used by multiple linear regression analysis and analysis of different test (ANOVA). Analysis of different test used to mengetaui differences in the level of service quality in the fourth manager or secretariat terdaat tourism and Pindul. The sample used for this study of 300 respondents, in the secretariat are 75 quota respondents. While multiple linear regression analysis is used to determine the quality of the services contained on Pindul sights on visitor satisfaction.

From the results of multiple linear regression analysis found that the variable contained in the study include (tangibles), reliability (reliability), responsiveness (reponsiveness), assurance (assurance) and empathy (empathy), proved positive and significant impact on visitor satisfaction sights Caves Pindul. While the results from different test proved that the differences in the level of service quality at every manager or secretarial attractions Pindul.
\end{abstract}

Keywords: Dimensions of quality, service, servqual, Cave Pindul

\begin{abstract}
Abstrak
Obyek wisata merupakan produk jasa yang ditawarkan oleh suatu perusahaan jasa dengan harapan agar pengunjung datang untuk berkunjung dan menikmati obyek wisata yang ditawarkan. Untuk dapat menarik minat pengunjung, pengelola harus dapat memberikan kualitas pelayanan terbaik untuk menciptakan suatu kepuasan terhadap pengunjung. Kualitas pelayanan mempunyai lima dimensi yang meliputi bukti langsung (tangibles), kehandalan (reliability), ketanggapan (reponsiveness), jaminan (assurance) dan empati (emphaty), kelima dimensi tersebut yang diacu dan dijadikan variabel dalam penelitian ini guna untuk mengetaui pengaruh kualitas jasa terhadap kepuasan pengunjung obyek wisata Gua Pindul.

Dalam penelitian ini pendekatan yang digunakan ialah kualitatif dengan analisis regresi linear berganda dan analisis uji beda (ANOVA). Analisis uji beda digunakan untuk mengetaui perbedaan tingkat kualitas jasa pada keempat pengelola atau sekretariat yang terdaat di obyek wisata Gua Pindul. Sample yang digunakan untuk penelitian ini sebanyak 300 responden, dalam satu sekretariat terdapat 75 kuota responden. Sedangkan analisis regresi linear berganda digunakan untuk mengetahui kualitas jasa yang terdapat pada obyek wisata Gua Pindul terhadap kepuasan pengunjung.
\end{abstract}


Dari hasil analisis regresi linear berganda diketahui bahwa variabel yang terdapat pada penelitian ini meliputi bukti langsung (tangibles), kehandalan (reliability), ketanggapan (reponsiveness), jaminan (assurance) dan empati (emphaty), terbukti berpengaruh positif dan signifikan terhadap kepuasan pengunjung obyek wisata Gua Pindul. Sedangkan hasil dari uji beda terbukti bahwa adanya perbedaan tingkat kualitas jasa pada tiap-tiap pengelola atau sekretariat obyek wisata Gua Pindul.

Kata Kunci: Dimensi Kualitas Jasa, layanan, Servqual, Gua Pindul

\section{Pendahuluan}

Daerah Istimewa Yogyakarta merupakan provinsi di Indonesia yang menyandang status "Daerah Istimewa". Dengan menyandang gelar sebagai "Daerah Istimewa" sebenarnya sudah merupakan sebuah kekuatan tersendiri bagi Yogyakarta. Berbagai potensi wisata yang dimiliki oleh Daerah Istimewa Yogyakarta adalah modal dasar pembangunan pariwisata. Namun, mengandalkan kekayaan alam, budaya, dan kesenian saja belum cukup untuk mendongkrak angka kunjungan wisatawan. Diperlukan organisasi pariwisata yang kuat dan langkah strategis untuk mengembangkan dan merancang pola pembangunan pariwisata. Peranan para pemangku kepentingan mulai dari pemerintah pusat dan daerah, pengusaha, Lembaga Swadaya Masyarakat, asosiasi pariwisata, para pemerhati dan peneliti pariwisata serta masyarakat umum yang secara langsung maupun tidak langsung ikut terlibat dalam kegiatan pariwisata.

Salah satunya Kabupaten Gunung Kidul yang semakin banyak diminati oleh wisatawan karena kabupaten tersebut banyak obyek wisata seperti wisata pantai, wisata gua, wisata budaya dan wisata alam. Salah satu wisata gua yang ada di kabupaten Gunung Kidul ialah obyek wisata Gua Pindul. Obyek wisata Gua Pindul merupakan obyek wisata berupa gua yang terletak di desa Bejiharjo, kecamatan Karangmojo, kabupaten Gunung Kidul. Gua Pindul merupakan obyek wisata yang menarik karena untuk menikmati keindahan Gua Pindul tidak seperti gua-gua pada umumnya, yakni dengan cara menyusuri gua yang dilakukan dengan menaiki ban pelampung di atas aliran sungai bawah tanah di dalam gua, kegiatan ini dikenal dengan istilah susur gua. Aliran sungai bawah tanah dimulai dari mulut gua sampai bagian akhir gua, di dalam gua terdapat bagian sempit yang hanya bisa dilewati satu ban pelampung, sehingga biasanya pengunjung akan bergantian untuk melewati bagian ini. Panjang Gua Pindul ialah 350 meter dengan lebar 5 meter dan jarak permukaan air dengan atap gua 4 meter, penelusuran Gua Pindul memakan waktu kurang lebih selama 45 menit yang berakhir pada sebuah dam. Aliran sungai yang berada di dalam Gua Pindul berasal dari mata air Gedong Tujuh.

Obyek wisata Gua Pindul diresmikan pada 10 Oktober 2010, pada mulanya Gua Pindul ditemukan oleh masyarakat sekitar dan diresmikan menjadi obyek wisata guna meningkatkan ekonomi warga sekitar. Gua Pindul dikelola oleh warga sekitar, pada awalnya pengelola Gua Pindul hanya memiliki satu pengelola/operator saja yakni Dewa Bejo, awal merintis obyek wisata Gua Pindul tentu banyak tantangan dan kendala akan tetapi pihak pengelola tidak menyerah yang awalnya jumlah kunjungan hanya beberapa orang mulai 
membuahkan hasil, jumlah tingkat kunjungan semakin meningkat dari tahun 2010-2015 hingga akhinya pada tahun 2012 tingkat kunjungan Gua Pindul melonjak signifikan sampai saat ini berikut rincian data yang diperoleh:

\section{Kunjungan Objek Wisata Gua Pindul}

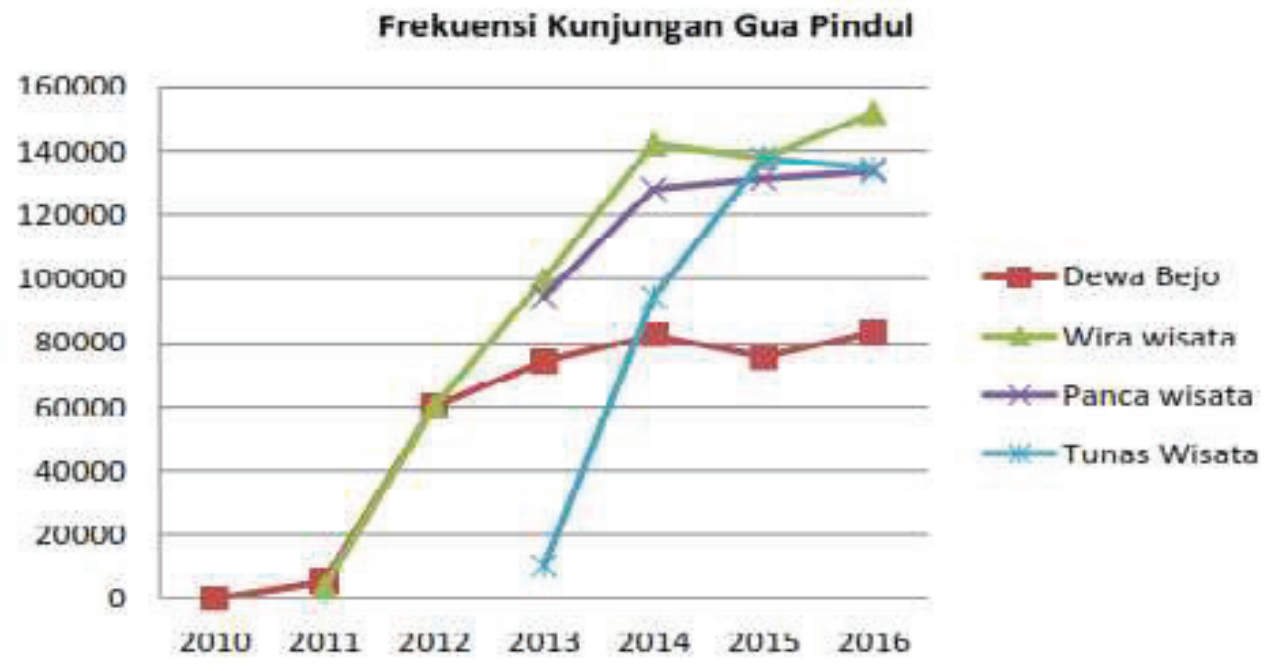

Sumber: Pengelola Obyek Wisata Gua Pindul

Dari grafik diatas dapat dilihat bahwa jumlah kunjungan obyek wisata Gua Pindul pertahun mengalami peningkatan, oleh karna itu banyak warga sekitar ingin menjadi pengelola Gua Pindul, hingga akhirnya bermunculan pengelola baru, tetapi sebelum pengelola baru mendirikan tempat harus menemukan dulu obyek wisata baru yang bereda disekitar Gua Pindul seperti Gua Seriti untuk menjadi icon pengelola tersebut, yang dimaksud dengan icon disini untuk menjadi identitas dari pengelola tersebut. Tanpa icon pengelola tidak bisa mendirikan tempat baru dan dianggap pengelola ilegal/tidak resmi. Pada saat ini ada empat pengelola resmi yang berada di Gua Pindul, pengelola tersebut ialah Dewa Bejo, Wira Wisata, Panja Wisata, dan Tuna Wisata. Yang menjadi induk serta panutan dari keempat pengelola tersebut ialah Dewa Bejo karena Dewa Bejo merupakan pengelola yang pertama kali berdiri. Setiap pengelola memiliki kedudukan yang sama seperti: (1)Memiliki struktur organsasi yang jelas; (2)Memiliki karyawan dan pemandu yang kompeten; (3)Menjual tiket dengan harga yang sama dengan yang lain; (4)Pemandu mendapatkan pelatihan serta sertifikat pelatihan dari dinas pariwisata Kabupaten Gunung Kidul; (5)Mimiliki strategi pemasaran guna menarik minat wisatawan untuk berkunjung.

Meskipun terdapat empat pengelola di dalam Gua Pindul setiap ketua pengelola tersebut selalu berkoordinasi dengan ketua-ketua dari pengelola lain, mengenai permasalahanpermasalah yang ada di Gua Pindul dan mencari solusinya secara bersama sama. Contoh permasalahan yang serius saat ini ialah Gua Pindul dalam segi pengelolaannya resmi diambil alih oleh Pemda, hanya saja saat ini Pemda belum mengambil alih keseluruhan dalam pengelolaannya, Pemda hanya menetapkan biaya kontribusi sebesar Rp.10.000/orang untuk memasuki Gua Pindul pengelolaan di dalam Gua Pindul tetap dikelola oleh keempat 
pengelola tersebut yaitu: ialah Dewa Bejo, Wira Wisata, Panja Wisata, dan Tuna Wisata. Akan tetapi, tidak menutup kemungkinan pada tahun yang akan datang pemda tidak hanya menetapkan biaya kontribusi, melainkan benar-benar mengambil alih pengelolaan secara keseluruhan terkait pengelolaan Gua Pindul.

Ditinjau dari segi pengelolaan yang terbagi atas empat pengelola/manajemen, hal ini tentu mempengaruhi pelayanan kualitas jasa yang disediakan oleh obyek wisata Gua Pindul karena tidak semua pengelola memiliki kualitas jasa yang sama, akan tetapi kualitas jasa bisa di standarkan agar kualitas jasa yang ada di Gua Pindul memiliki standar yang sama seperti: (1) karyawan yang bertugas harus rapi dan ramah; (2) pemandu memberikan penjelasan dan pengarahan dengan baik; (3) pemandu harus respek/peka terhadap pengunjung yang hendak celaka dalam penyusuran gua; (4) pemandu memiliki skill berenang karena penting untuk menyelamatkan pengunjung yang hendak tenggelam. Jika tidak memiliki standar kualitas jasa, tentu akan mempengaruhi citra Gua Pindul terhadap wisatawan karena wisatawan yang berkunjung ke Gua Pindul tidak mengetahui bahwa Gua Pindul terdiri atas empat pengelola. Jadi, misalkan pen gelola Dewa Bejo memberikan kualitas jasa yang buruk terhadap pengunjungnya maka nama Gua Pindullah yang kualitas jasanya terkesan buruk dimata pengunjung bukan pengelola Dewa Bejo, hal ini tentu akan merugikan bagi pengelola yang lain. Oleh karena itu, penting untuk mengetahui kualitas jasa saat ini yang disediakan oleh keempat pengelola yang ada di Gua Pindul terkait kepuasan pengunjung. Berdasarkan latar belakang yang telah dipaparkan sebelumnya, maka penulis merumuskan masalah pada penelitian ini sebagai berikut:

1. Apakah terdapat pengaruh kualitas jasa mencakup (dimensi bukti fisik, kehandalan, daya tanggap, jaminan dan empati) terhadap kepuasan pengunjung obyek wisata Gua Pindul?

2. Apakah terdapat perbedaan tingkat kualitas jasa (dimensi bukti fisik, kehandalan, daya tanggap, jaminan dan empati) terhadap lima pengelola (Dewa Bejo, Wira Wisata, Panca Wisata, dan Tunas Wisata) dalam pengelolaan obyek wisata Gua Pindul?

Dari rumusan masalah yang telah diuraikan di atas maka peneliti membuat hipotesis sebagai berikut:

\section{Hipotesis mayor}

Terdapat pengaruh kualitas jasa terhadap kepuasan pengunjung obyek wisata Gua Pindul.

\section{Hipotesis minor}

$\mathrm{H}_{1}$ : Dimensi bukti fisik berpengaruh positif dan signifikan terhadap kepuasan pengunjung obyek wisata Gua Pindul.

$\mathrm{H}_{2}$ : Dimensi kehandalan berpengaruh positif dan signifikan terhadap kepuasan pengunjung obyek wisata Gua Pindul.

$\mathrm{H}_{3}$ : Dimensi daya tanggap berpengaruh positif dan signifikan terhadap kepuasan pengunjung obyek wisata Gua Pindul.

$\mathrm{H}_{4}$ : Dimensi jaminan berpengaruh positif dan signifikan terhadap kepuasan pengunjung obyek wisata Gua Pindul. 
$\mathrm{H}_{5}$ : Dimensi empati berpengaruh positif dan signifikan terhadap kepuasan pengunjung obyek wisata Gua Pindul.

$\mathrm{H}_{6}$ : Tingkat kualitas jasa pengelola (Dewa Bejo, Wira Wisata, Panca Wisata, dan Tunas Wisata) berpengaruh positif terhadap kepuasan pengunjung.

H7 : Terdapat perbadaan tingkat kualitas jasa pengelola (Dewa Bejo, Wira Wisata, Panca Wisata, dan Tunas Wisata).

\section{Tinjauan Pustaka dan Kajian Teori}

Berdasarkan penelitian (Laili, 2013: 40) yang berjudul analisis kualitas pelayanan terhadap kepuasan pengunjung Lawang Sewu. Variabel yang digunakan mengacu pada model SERVQUAL (service quality). Hasil yang diperoleh dari penelitian tersebut ialah variabel keandalan tidak berpengaruh secara signifikan terhadap kepuasan pelanggan, sedangkan bukti fisik, jaminan, daya tanggap dan empati berpengaruh secara signifikan terhadap kepuasan pelanggan. Hal ini berbeda dengan penelitian (Prasetyo, 2009: 29) yang berjudul pengaruh kualitas pelayanan terhadap kepuasan pengunjung pada obyek wisata taman rekreasi pantai kartini rembang. Berdasarkan hasil penelitian menunjukkan bahwa tangibles (bukti langsung), reliability (kehandalan), responsiveness (ketanggapan), assurance (jaminan) dan emphaty (empati) memberikan kontribusi secara signifikan terhadap kepuasan pengunjung.

Saat ini, konsep kualitas pelayanan atau jasa telah menjadi suatu "credo" universal dan telah menjadi faktor yang dominan terhadap keberhasilan suatu organisasi. Service quality tidak hanya diadopsi oleh lembaga penyelenggara jasa-jasa komersial, tetapi juga telah merembes ke lembaga-lembaga pemerintahan, yang selama ini resisten terhadap tuntutan kualitas pelayanan publik yang prima (Sulistyani, 2001: 56).

Pada prinsipnya, setiap perusahaan atau obyek wisata harus mampu memuaskan dan mempertahankan pelanggan (customer satisfaction). Hal ini adalah kunci untuk mempertahankan kinerja bisnis. Dengan memberikan kepada pelanggan "alasan yang kuat untuk mengunjungi tempat wisata tersebut dan tidak mengganti destinasi" berarti perusahaan telah mengisolasi mereka dari tekanan kompetisi (Johnson \& Gustafsson, 2000:101). Para pemasar tahu bahwa "bagaimana cara untuk memikat hati para pelanggan tidak hanya menghantarkannya ke tempat tujuan" merupakan hal terpenting bagi perusahaan. Oleh karena itu, tidak mengherankan jika kepuasan pelanggan menjadi tujuan utama dari perusahaan-perusahaan yang inovatif. Bahkan seringkali menerapkan konsep dengan menumbuhkan alasan yang kuat atau prioritas utama kepada pelanggan dalam setiap kegiatan bisnis.

Kualitas jasa berpusat pada upaya pemenuhan kebutuhan dan kerugian pelanggan serta ketetapan penyampaian untuk mengimbangi harapan pelanggan. Kualitas jasa menurut (Tjiptono, 2006:59) adalah suatu kondisi dinamis yang berhubungan dengan produk, jasa, manusia, proses, dan lingkungan yang memenuhi atau melebihi harapan. Sedangkan (Tjiptono, 2011:67) kualitas jasa lebih sulit didefinisikan, dijabarkan, dan diukur apabila dibandingkan dengan kualitas barang, karena jasa lebih bersifat intangible dan lebih merupakan proses yang dialami konsumen secara subjektif, dimana efektivitas produksi dan konsumsi berlangsung 
pada saat bersamaan. Selama proses tersebut berlangsung, terjadi interaksi yang meliputi serangkaian moment of truth antara konsumen dan penyedia jasa. Apa yang terjadi selama interaksi tersebut (disebut juga interaksi pembeli - penjual atau service encounters) akan sangat berpengaruh terhadap jasa yang dipersiapkan oleh konsumen. Kemudian yang dimaksud dengan kepuasan konsumen/pengunjung adalah respon jawaban dari konsumen/pengunjung. Hal itu merupakan suatu penilaian bahwa sebuah fitur produk atau jasa itu sendiri menyediakan tingkat pemenuhan konsumsi yang menyenangkan. Kepuasan merupakan evaluasi konsumen/pengunjung terhadap suatu produk atau layanan dalam hal apakah layanan atau produk itu telah memenuhi kebutuhan dan harapan konsumen/pengunjung. Kegagalan untuk memenuhi kebutuhan dan harapan konsumen/pengunjung akan menghasilkan ketidakpuasan terhadap produk atau layanan tersebut. (Kotler, 2000:102) mengatakan bahwa kepuasan konsumen/pelanggan merupakan tingkat perasaan seseorang setelah membandingkan antara kinerja produk yang ia rasakan dengan harapannya. Kepuasan atau ketidakpuasan konsumen/pelanggan ialah respon terhadap evaluasi ketidaksesuaian atau diskonfirmasi yang dirasakan antara harapan sebelumnya dan kinerja aktual produk yang dirasakan setelah pemakaian.

\section{Metode Penelitian}

Metode penelitian yang digunakan dalam penelitian ini adalah metode kuantitatif, dengan pendekatan survei. Metode kuantitatif ialah merupakan salah satu penelitian yang spesifikasinya adalah sistematis, terencana, dan terstruktur dengan jelas sejak awal hingga pembuatan desain penelitiannya. Jenis penelitian yang digunakan dalam penelitian ini adalah studi korelasi, yaitu studi yang berusaha mengamati hubungan antar variabel yang diteliti.

Obyek penelitian : : Obyek Wisata Gua Pindul

Subjek Penelitian : : Pengunjung Obyek Wisata Gua Pindul

Waktu Pelaksanaan : 21 Mei -31 Juli

Variabel Penelitian

Terdapat dua variabel dalam penelitian ini, yaitu kualitas jasa dan kepuasan pengunjung. Metode pencuplikan data menggunakan accidental sampling dan quota sampling. Alat yang akan dipakai untuk mendapatkan data dari penelitian ini ialah menggunakan kuesioner. Pengumpulan data dalam penelitian ini menggunakan teknik kuesioner. Kuesioner yang disebar sebanyak 300 responden, dalam satu sekretariat mendapat jumlah kuota kuesiner sebnyak 75 kuesioner.

Data didokumentasikan dalam dua bentuk yakni hardcopy dan softcopy. Hardcopy berupa kuesioner yang diisi langsung oleh responden. Data softcopy merupakan data yang telah dikelompokkan ke dalam program Microsoft Excell.

Dalam penelitian ini, skala yang digunakan untuk pengukuran data ialah menggunakan skala likert. Skala likert adalah skala yang digunakan umtuk mengukur sikap, pendapat, dan persepsi seseorang tentang suatu obyek atau fenomena tertentu. Skala likert memiliki dua bentuk pertanyaan, yaitu pertanyaan positif dan negatif. Pertanyaan positif diberi skor 5,4,3,2, dan 1 , sedangkan untuk pertanyaan negatif diberi skor 1, 2, 3, 4, dan 5. Bentuk jawaban skala 
likert terdiri dari sangat setuju, setuju, netral, tidak setuju, dan sangat tidak setuju. Teknik analisis menggunakan regresi linear berganda dan uji beda ANOVA

\section{Temuan dan Pembahasan}

\section{Hasil Analisis Regresi Linear Berganda}

Analisis dalam penelitian ini adalah analisis Regresi Linear Berganda. Analisis ini digunakan untuk mengetahui pengaruh variabel independen yaitu bukti fisik (X1), kehandalan (X2), daya tanggap (X3), jaminan (X4), dan empati (X5) terhadap variabel dependen yaitu kepuasan pengunjung obyek wisata Gua Pindul (Y). Adapun bentuk persamaan regresinya adalah $\mathrm{Y}=\mathrm{b}_{0}+\mathrm{b}_{1} \mathrm{X}_{1}+\mathrm{b}_{2} \mathrm{X}_{2}+\mathrm{b}_{3} \mathrm{X}_{3}+\mathrm{b}_{4} \mathrm{X}_{4}+\mathrm{b}_{5} \mathrm{X}_{5}+\mathrm{e}_{\mathrm{i}}$. Berikut ini tabel hasil Regresi Berganda metode OLS (Ordinary Least Square).

Hasil Uji Regresi Linear Berganda

\begin{tabular}{|l|c|c|c|c|}
\hline \multicolumn{1}{|c|}{ Variabel } & $\begin{array}{c}\text { Koefisien } \\
\text { Regresi }\end{array}$ & $\begin{array}{c}\text { Standart } \\
\text { Error }\end{array}$ & t-hitung & Probabilitas \\
\hline Konstanta & 6,260 & 0,741 & 8,449 & 0,000 \\
\hline Bukti Fisik (X1) & 0,283 & 0,130 & 2,174 & 0,031 \\
\hline Kehandalan (X2) & 0,392 & 0,154 & 2,539 & 0,012 \\
\hline Daya Tanggap (X3) & 0,406 & 0,152 & 2,665 & 0,008 \\
\hline Jaminan (X4) & 0,301 & 0,134 & 2,242 & 0,026 \\
\hline Empati (X5) & 0,304 & 0,151 & 2,011 & 0,045 \\
\hline $\mathrm{R}^{2} 0,083$ & \\
\hline Adjusted ${ }^{2}: 0,067$ \\
\hline F-statistik : 5,302, Sig. $=0,000$. \\
\hline $\mathrm{N}$ \\
\hline Variabel Dependen : Kepuasan Pengunjung (Y) \\
\hline
\end{tabular}

Berdasarkan hasil perhitungan dengan menggunakan program statistik komputer

SPSS for windows diperoleh hasil persamaan Regresi Linear Berganda sebagai berikut : $\mathrm{Y}=$ $6,260+0,283+0,392 \mathrm{X}_{2}+0,406 \mathrm{X}_{3}+0,301 \mathrm{X}_{4}+0,304 \mathrm{X}_{5}$

Pada persamaan di atas ditunjukkan pengaruh variabel bukti fisik (X1), kehandalan (X2), daya tanggap (X3), jaminan (X4), dan empati (X5) terhadap kepuasan Pengunjung obyek wisata Gua Pindul (Y). Adapun arti dari koefisien regresi tersebut adalah:

1) Konstanta $\left(\mathrm{b}_{0}\right)=6,260$

Pada persamaan di atas nilai konstanta diproleh sebesar 6,260 (positif) yang berarti bahwa jika skor pada bukti fisik (X1), kehandalan (X2), daya tanggap (X3), jaminan (X4), dan empati (X5), sama dengan nol, maka kepuasan Pengunjung obyek wisata Gua Pindul (Y) sama dengan 6,260.

2) Koefisien regresi bukti fisik (b1) $=0,283$ 
Koefisien regresi positif (searah) artinya, jika bukti fisik (X1) meningkat, maka kepuasan Pengunjung obyek wisata Gua Pindul (Y) akan meningkat dan sebaliknya, dengan asumsi variabel independen lain konstan.

3) Koefisien regresi kehandalan (b2) $=0,392$

Koefisien regresi positif (searah) artinya, jika kehandalan (X2) meningkat, maka kepuasa Pengunjung obyek wisata Gua Pindul (Y) akan meningkat dan sebaliknya, dengan asumsi variabel independen lain konstan.

4) Koefisien regresi daya tanggap (b3) $=0,406$

Koefisien regresi positif (searah) artinya, jika daya tanggap (X3) meningkat, maka kepuasan Pengunjung obyek wisata Gua Pindul (Y) akan meningkat dan sebaliknya, dengan asumsi variabel independen lain konstan.

5) Koefisien regresi jaminan (b4) $=0,301$

Koefisien regresi positif (searah) artinya, jika jaminan (X4) meningkat, maka kepuasan Pengunjung obyek wisata Gua Pindul (Y) akan meningkat dan sebaliknya, dengan asumsi variabel independen lain konstan.

6) Koefisien regresi empati (b5) $=0,304$

Koefisien regresi positif (searah) artinya, jika empati (X5) meningkat, maka Kepuasan Pengunjung obyek wisata Gua Pindul (Y) akan meningkat dan sebaliknya, dengan asumsi variabel independen lain konstan.

Dalam penelitian ini uji $\mathrm{T}$ digunakan untuk membuktikan pengaruh antara variabel bukti fisik, kehandalan, daya tanggap, jaminan, dan empati terhadap kepuasan pengunjung obyek wisata Gua Pindul secara parsial. Berdasarkan hasil perhitungan dengan menggunakan program statistik komputer SPSS for windows dilakukan pengujian hipotesis sebagai berikut :

1. Pengujian hubungan variabel bukti fisik $\left(\mathrm{X}_{1}\right)$ dengan Kepuasan Pengunjung obyek wisata Gua Pindul (Y).

- Dengan taraf nyata $(\alpha)=5 \%=0,05$ dan hasil perhitungan regresi linear berganda diperoleh nilai probabilitas-statistik (sig.) $=0,031$.

- Berdasarkan hasil olah data diperoleh nilai probabilitas-statistik (sig.) =0,031< level of significant $=0,05$, maka diketahui bahwa ada pengaruh signifikan antara bukti fisik (X1) terhadap Kepuasan Pengunjung obyek wisata Gua Pindul (Y).

2. Pengujian hubungan variabel kehandalan (X2) dengan Kepuasan Pengunjung obyek wisata Gua Pindul (Y).

- Dengan taraf nyata $(\alpha)=5 \%=0,05$ dan hasil perhitungan regresi linear berganda diperoleh nilai probabilitas-statistik (sig.) $=0,012$.

- Berdasarkan hasil olah data diperoleh nilai probabilitas-statistik (sig.) $=0,012<$ level of significant $=0,05$, maka diketahui bahwa ada pengaruh signifikan antara kehandalan (X2) terhadap Kepuasan Pengunjung obyek wisata Gua Pindul (Y).

3. Pengujian hubungan variable daya tanggap (X3) dengan Kepuasan Pengunjung obyek wisata Gua Pindul (Y).

- Dengan taraf nyata $(\alpha)=5 \%=0,05$ dan hasil perhitungan regresi linear berganda diperoleh nilai probabilitas-statistik (sig.) $=0,008$. 
- Berdasarkan hasil olah data diperoleh nilai probabilitas-statistik (sig.) $=0,008<$ level of significant $=0,05$, maka diketahui bahwa ada pengaruh signifikan antara daya tanggap (X3) terhadap Kepuasan Pengunjung obyek wisata Gua Pindul (Y).

4. Pengujian hubungan variabel jaminan (X4) dengan Kepuasan Pengunjung obyek wisata Gua Pindul (Y).

- Dengan taraf nyata $(\alpha)=5 \%=0,05$ dan hasil perhitungan regresi linear berganda diperoleh nilai probabilitas-statistik (sig.) $=0,026$.

- Berdasarkan hasil olah data diperoleh nilai probabilitas-statistik (sig.) $=0,026<$ level of significant $=0,05$, maka diketahui bahwa ada pengaruh signifikan antara jaminan (X4) terhadap Kepuasan Pengunjung obyek wisata Gua Pindul (Y).

5. Pengujian hubungan variabel empati (X5) dengan Kepuasan Pengunjung obyek wisata Gua Pindul (Y).

- Dengan taraf nyata $(\alpha)=5 \%=0,05$ dan hasil perhitungan regresi linear berganda diperoleh nilai probabilitas-statistik (sig.) $=0,045$.

- Berdasarkan hasil olah data diperoleh nilai probabilitas-statistik (sig.) $=0,045<$ level of significant $=0,05$, maka diketahui bahwa ada pengaruh signifikan antara empati (X5) terhadap Kepuasan Pengunjung obyek wisata Gua Pindul (Y).

Uji $\mathrm{F}$ adalah uji secara bersama-sama yang digunakan untuk mengetahui pengaruh variabel bukti fisik (X1), kehandalan (X2), daya tanggap (X3), jaminan (X4), dan empati (X5) terhadap kepuasan Pengunjung obyek wisata Gua Pindul (Y). Diperoleh nilai probabilitas F hitung $=0,000<$ level of significant $=0,05$, maka Ho ditolak atau Ha diterima, artinya ada pengaruh secara bersama-sama variabel bukti fisik (X1), kehandalan (X2), daya tanggap (X3), jaminan (X4), dan empati (X5) terhadap kepuasan pengunjung obyek wisata Gua Pindul (Y).

\section{Hasil Uji ANOVA}

Berdasarkan hasil olah data nilai ANOVA variabel penelitian sebagai berikut:

Hasil Uji ANOVA

\begin{tabular}{|l|c|c|}
\hline \multicolumn{1}{|c|}{ Variabel } & F-hitung & Sig. \\
\hline Bukti Fisik (X1) & 11,965 & 0,000 \\
\hline Kehandalan (X2) & 2,150 & 0,049 \\
\hline Daya Tanggap (X3) & 7,982 & 0,000 \\
\hline
\end{tabular}




\begin{tabular}{|l|l|l|}
\hline Jaminan (X4) & 25,925 & 0,000 \\
\hline Empati (X5) & 6,272 & 0,000 \\
\hline
\end{tabular}

Pada di atas, nilai probabilitas F-hitung variabel bukti fisik (X1), kehandalan (X2), daya tanggap (X3), jaminan (X4), dan empati (X5) < level of significant $=0,05$, maka Ho ditolak atau Ha diterima, artinya ada perbedaan signifikan variabel bukti fisik (X1), kehandalan (X2), daya tanggap (X3), jaminan (X4), dan empati (X5) antara pengelola jasa (Dewa Bejo, Wira Wisata, Panca Wisata, dan Tunas Wisata). Selanjutnya untuk mengetahui seberapa besar atau significant perbedaan kualitas jasa yang meliputi variabel bukti fisik, kehandalan, jaminan, empati dan daya tanggap. Kemudian untuk mengatahui seberapa besar perbedaan kualitas jasa pada setiap sekretariat bisa dilihat pada tabel nilai mean service quality.

Hasil Nilai Mean Service Quality

\begin{tabular}{|c|c|c|c|c|}
\hline \multirow{2}{*}{ Variabel } & \multicolumn{4}{|c|}{ Nilai Mean } \\
\cline { 2 - 5 } & $\begin{array}{c}\text { Wira } \\
\text { Wisata }\end{array}$ & $\begin{array}{c}\text { Dewa } \\
\text { Bejo }\end{array}$ & Panca Wisata & Tunas Wisata \\
\hline Bukti fisik & 3,71 & 3,62 & 3,42 & $\mathbf{3 , 2 9}$ \\
\hline Kehandalan & 3,78 & 3,75 & $\mathbf{3 , 6 8}$ & 3,77 \\
\hline Daya Tanggap & 3,91 & 3,77 & 3,69 & $\mathbf{3 , 5 6}$ \\
\hline Jaminan & 3,92 & 3,98 & 3,68 & $\mathbf{3 , 3 8}$ \\
\hline Empati & 3,75 & 3,68 & 3,54 & $\mathbf{3 , 4 6}$ \\
\hline Nilai Mean service quality & 3.814 & 3.760 & 3.602 & $\mathbf{3 . 4 9 2}$ \\
\hline
\end{tabular}

Berdasarkan tabel di atas, dapat dilihat bahwa nilai mean service quality setiap sekretariat pada variabel bukti fisik menyatakan bahwa sekretariat Wira Wisata memiliki nilai mean tertiggi dengan nilai 3,71 yang artinya menyatakan service quality atau kualitas jasa pada sekretariat Wira Wisata sangat baik jika dibandingkan dengan sekretariat lainnya, sedangkan untuk secretariat Tunas Wisata memiliki nilai mean 3,29 yang artinya menyatakan service quality atau kualitas jasa pada sekretariat tersebut sangat rendah atau kurang baik. Diharapkan pengelola sekretariat Tunas Wisata untuk lebih memperhatikan tempat parkir, peralatan yang digunakan untuk penyusuran gua seperti pelampung, sepatu, dan ban serta memperhatikan penampilan karyawan dan kebersihan lingkungan. Hal-hal tersebut dinyatakan kurang baik dan harus diperhatikan agar service quality pada variabel bukti fisik menjadi lebih baik.

Selanjutnya, untuk variabel kehandalan dapat dilihat bahwa nilai mean service quality pada sekretariat tersebut meliputi Dewa Bejo, Wira Wisata, Tunas Wisata dan Panca Wisata. Service quality atau kualitas jasa yang sangat baik meskipun terdapat perbedaan nilai mean pada service quality akan tetapi perbedaan tersebut tidak terlalu jauh. Hal ini menyatakan bahwa guide pada tiap-tiap secretariat menyediakan pelayanannya sesuai dengan waktu yang dijanjikan. Dalam setiap rombongan dipandu dua guide, karyawan atau petugas memberikan informasi secara jelas, jika guide menjanjikan sesuatu maka akan ditepati dan tempat penitipan 
barang pengunjung sangat aman. Hal-hal tersebut dinyatakan sudah bagus dan harus dipertahankan agar service quality pada variabel kehandalan tetap baik.

Kemudian untuk variabel daya tanggap dapat dilihat bahwa nilai mean service quality setiap sekretariat pada variabel daya tanggap menyatakan bahwa sekretariat Wira Wisata memiliki nilai mean tertiggi dengan nilai 3,91 yang artinya menyatakan service quality atau kualitas jasa pada sekretariat Wira Wisata sangat baik jika dibandingkan dengan sekretariat lainnya, sedangkan untuk sekretariat Tunas Wisata memiliki nilai mean 3,56 yang artinya menyatakan service quality atau kualitas jasa pada sekretariat tersebut sengat rendah atau kurang baik diharapkan pengelola sekretariat Panca Wisata untuk lebih memperhatikan secara sigap dan tanggap dalam hal menolong pengunjung yang hendak celaka, secara tanggap menengani keluhan pengunjung, melanyani pengunjung dalam pembelian tiket dengan tanggap dan sigap tanpa kesalahan, dan memandu pengunjung dengan jelas tidak membingungkan. Hal-hal tersebut dinyatakan kurang baik dan harus diperhatikan agar service quality pada variabel daya tanggap menjadi lebih baik.

Pada variabel jaminan dapat dilihat bahwa nilai mean service quality setiap sekretariat pada variabel jaminan menyatakan bahwa sekretariat Dewa Bejo memiliki nilai mean tertiggi dengan nilai 3,98 yang artinya menyatakan service quality atau kualitas jasa pada sekretariat Wira Wisata sangat baik jika dibandingkan dengan sekretariat lainnya, sedangkan untuk sekretariat Tunas Wisata memiliki nilai mean 3,38 yang artinya menyatakan service quality atau kualitas jasa pada sekretariat tersebut sengat rendah atau kurang baik diharapkan pengelola sekretariat Tunas Wisata untuk lebih memperhatikan keselamatan pegunjung, pemandu bersikap ramah dan sopan terhadap pengunjung, pemendu dapat menjelskan apa yang terdapat di dalam gua dan menjawab pertanyaan pengunjung serta pemendu yang profesional dalam hal tepat waktu, komunikasi yang baik dan menguasai medan saat susur gua. Hal-hal tersebut dinyatakan kurang baik dan harus diperhatikan agar service quality pada variabel jaminan menjadi lebih baik.

Dan yang terhakhir Pada variabel empati dapat dilihat bahwa nilai mean service quality setiap sekretariat pada variabel empati menyatakan bahwa sekretariat Wira Wisata memiliki nilai mean tertiggi dengan nilai 3,75 yang artinya menyatakan service quality atau kualitas jasa pada sekretariat Wira Wisata sangat baik jika dibandingkan dengan sekretariat lainnya, sedangkan untuk sekretariat Tunas Wisata memiliki nilai mean 3,46 yang artinya menyatakan service quality atau kualitas jasa pada sekretariat tersebut sengat rendah atau kurang baik diharapkan pengelola sekretariat Tunas Wisata untuk lebih memperhatikan jam operasi kunjungan sesui dengan yang dijadwalkan, pemberian asuransi kecelakaan kepada pngunjung, pengunjung mendapat perhatiaan penuh saat susur gua, guide bersungguhsungguh dalam memperhatikan kepentingan pengunjung dan fasilitas umum seperti kamar mandi, mushola, dan kantin diperhatikan sesuai kebutuhan pengunjung. Hal-hal tersebut dinyatakan kurang baik dan harus diperhatikan agar service quality pada variabel jaminan menjadi lebih baik. Jika dilihat dari skor total service qua;ity pada keempat sekretariat tersebut maka disimpulkan bahwa sekretariat Wira Wisata memang memiliki service quality atau kualitas jasa yang terbaik jika dibandingkan dengan sekretariat lain dengan skor total 3,814 sedangkan untuk sekretariat yang memiliki service quality rendah atau kurang baik yaitu sekretariat Tunas Wisata dengan skor total nilai mean 3,492. 
Berdasarkan pemaparan di atas jika dikaitkan dengan grafik kunjungan 1.1 halaman 6. Hasil analisis yang sudah diperoleh berdasarkan service quality atau kualita jasa sekretariat Dewa Bejo memperoleh hasil service quality lebih baik jika dibandingkan dengan sekretariat panca wisata dan Tunas Wisata akan tetapi dari segi jumlah kunjungannya lebih banyak Panca Wisata dan Tuna Wisata. Hal ini dapat diasumsikan bahwa tingkat kualitas jasa atau service quality yang baik belum tentu jumlah kunjungan obyek wisata menjadi banyak. Akan tetapi disisi lain berdasrkan dari hasil analisi kualitas jasa sekretariat Wira Wisata memeng memiliki service quality yang paling baik dibandingkan dengan yang lain dan dari segi jumlah kunjungan memang lebih unggul dibandingkan dengan yang lain.

\section{Kesimpulan}

1. Dari hasil analisis regresi linear berganda menyatakan bahwa adanya pengaruh kualitas jasa terhadap variabel bukti fisik, daya tanggap, kehandalan, jaminan dan empati terhadap kepuasan pengunjung obyek wisata Gua Pindul. Hal ini dibuktikan dengan pengujian hipotesis dari hasil uji $\mathrm{T}$ dan uji $\mathrm{F}$ bahwa ke lima variabel tersebut memiliki pengaruh positif dan signifikan terhadap kepuasan pengunjung baik secara parsial atau bersama-sama dengan nilai signifikan untuk variabel bukti fisisk 0,031 , kehandalan 0,12 , daya tanggap 0,008 , jaminan 0,026 dan empati 0,045 .

2. Dari hasil analisis uji ANOVA menyatakan bahwa terdapat adanya perbedaan service quality atau kualitas jasa untuk variabel bukti fisik, kahandalan, daya tanggap, jaminan dan empati terhadap sekretariat Pengelola Obyek Wisata Gua Pindul, yaitu: Dewa Bejo, Wira Wisata, Panca Wisata dan Tuna Wisata dapat diuraikan sebagai berikut:

a. Dewa Bejo: berdasarkan hasil analisis dan pengamatan sekretariat Dewa Bejo memiliki kualitas yang baik atau bagus pada setiap variabel bukti fisik, daya tanggap, kehandalan, jaminan dan empati. Akan tetapi untuk variabel kehandalan sedikit lebih rendah service quality atau kualitas jasanya jika dibandingkan dengan sekretariat lain yang artinya pada variabel ini perlu adanya perhatian agar menjadi lebih baik lagi .

b. Wira Wisata: berdasarkan hasil analisis dan pengamatan sekretariat Wira Wisata memiliki service quality atau kualitas jasa yang bagus pada setiap variabel yang artinya kebersihan tempat wisata, keramahtamahan petugas, kerapian petugas, pemberian informasi secara jelas, tempat penitipan barang yang aman, jaminan keselamatan, kesigapan petugas dalam menangani keluhan pengunjung, guide yang profesional, dan pemberian asuransi terhap pengunjung sudah dinyatakan memiliki service quality atau kualitas jasa yang baik. Disisi lain jika dibandingkan dengan sekretariat lainnya sekretariat Wira Wisata dominan memiliki service quality atau kualitas jasa yang baik pada setiap variabel. 
c. Panca Wisata: berdasarkan hasil analisis dan pengamatan sekretariat Panca Wisata memiliki service quality atau kualiatas jasa yang baik pada setiap variabel meliputi bukti fisik, kehandalan, daya tanggap, empati dan jaminan akan tetapi untuk variabel bukti fisik service quality atau kualitas jasanya sedikit lebih rendah yang artinya pada variabel ini perlu adanya perhatian agar menjadi lebih baik lagi.

d. Tunas Wisata: berdasarkan hasil analisis dan pengamatan sekretariat panca wisata memiliki service quality atau kualitas jasa yang kurang baik atau kurang bagus pada variabel bukti fisik, jaminan, empati dan daya tanggap yang artinya pengelola sekretariat Tunas Wisata harus lebih memperhatikan service quality atau kualitas jasa yang mereka sediakan karena jika dibandingkan dengan sekretariat lain sekretariat Tunas Wisata dominan memiliki service quality rendah yang artinya pada variabel ini perlu adanya perhatian agar menjadi lebih baik lagi. Disisi lain hanya terdapat satu variabel yang service quality atau kualitas jasanya baik yaitu variabel kehandalan.

\section{Kepustakaan}

Ancok, Djamaludin. 2012. Psikologi Kepemimpinan dan Inovasi. Erlangga : Jakarta.

Bhat, V. And J. Cozzolino. 1993. Total Quality: An Effective Management Tools.

Cook, Sarah. 2002. Customer Care Excellence : How to create and Effective Customer Fokus. New York : Kogan Page Publisher.

Dale, M.2003. Developing Management Skills Terjemahan . Jakarta: PT Gramedia

Engel, J.F., R.D, Blackwell., and P.W, Miniard, 1994. Perilaku Konsumen. Jakarta: Binarupa Aksara

Ferrinadewi, E, 2008. Merek dan Psikologi Konsumen. Yogyakarta: Graha ilmu. Griffin, Jill, 1995, Customer Loyalty : How to Earn It, How to Keep It. New York: Lexington Books.

Jones, Thomas O., \& Sasser, Jr., W. Earl, 1997, Why Satisfied Customer Defect, Harvard Business Review, Nov - Dec.

Juran, J. M. 1989. Juran on Leadership for Quality, The Free Press, MacMillan,Inc. E. Nugroho (penterjema). 1995. Kepe-mimpinan Mutu. Pustaka Binaman Pressindo, Jakarta.

Keaveney, Susan M., 1995, Customer Switching Behavior in Service Industries: an Exploratory Study, Journal of Marketing, Vol.59, April, 71-82.

Kennedy, Carol,1996, Managing with the Gurus (Mengelola Bersama Para Guru), Jakarta: Elex Media Komputindo.

Kotler, P, 1997. Marketing Management:Analysis, Planing, Implementation and Control, 9th Prentice Hall. Upper Sadle Riverss. New Jersey

Kotler, Philip. 2000. Manajemen Pemasaran : Analisis, Perencanaan, Implementasi dan Kontrol, Edisi Terjemahan. Prentice Hall. Inc.

Kotler, Philip. 2008. Manajemen Pemasaran Edisi Millenium Terjemahkan Benyamin Molant. Jakarta: PT. Prenhallindo

Kristianto, L.P, 2011. Psikologi Pemasaran, Yogyakarta: CAPS

Lupiyoadi, Rambat dan Hamdani, A., 2009. Manajemen Pemasaran, Edisi 2. Salemba Empat. Jakarta. 
Parasuraman, A., VA Zeithaml, dan L.L. Berry. 1985). "A Conceptual Model of Service Quality and Its Implicationes For Future Research”. Journal of Marketing, Vol. 69 Fall : 41-50.

Parasuraman, A., VA Zeithaml, dan L.L. Berry. 1988). "SERVQUAL : A Multiple- Item Scale for Measuring Consumer Perceptions of Service Quality", Journal of Retailing, Vol.64 Spring :12-40.

Prasetyo, Dwi. 2009. Pengaruh Kualitas Pelayanan Terhadap Kepuasan Pengunjung Pada Obyek Wisata Taman Rekreasi Pantai Kartini Rembang. Universitas Negri Semarang. Semarang.

Priyatno, D. 2009. Spss Untuk Analisis Korelasi, Regresi, Dan Multivariate. Yogyakarta: Gava Media.

Reichheld, F.F. (1996), The Loyalty Effect, Harvard Business School Press, Boston, MA. R.P Kresnamurti Agung dan Sinambela Siskawati Dian. 2011. Analisis Kualitas Pelayanan Serta Pengaruhnya Terhadap Kepuasan Pelanggan Dan Loyalitas Pelanggan. Jurnal Fakultas Ekonomi Vol.02. No.02. Universitas Negri Jakarta, Jakarta. 